\title{
REVISTAMARACANAN
}

\section{COTA JUNIOR, Eustáquio Ornelas. A formação da coleção latino-americana do MoMA: Arte, cultura e política (1931- 1943). Jundiaí, SP: Paco, 2019. 236 p.}

\section{Resenha}

Recebido em: 05 abr. 2020.

Aprovado em: 23 jul. 2020.

\author{
Igor Lemos Moreira* \\ Universidade do Estado de Santa Catarina \\ Florianópolis, Santa Catarina, Brasil
}

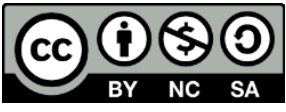

Palavras-chave: Arte Latino-Americana. Museu de Arte Moderna de Nova York. Acervos e Museus.

Keywords: Latin American Art. MoMA. Collections and Museums.

O presente trabalho foi realizado com apoio da Coordenação de Aperfeiçoamento de Pessoal de Nível Superior - CAPES, Brasil. Código de Financiamento 001.

* Doutorando no Programa de Pós-graduação em História da Universidade do Estado de Santa Catarina. Mestre e Licenciado em História pela Universidade do Estado de Santa Catarina. (igorlemoreira@gmail.com)

(iD) https://orcid.org/0000-0001-6353-7540

(9) http://lattes.cnpq.br/2889830742673964 
Publicada pela Paco Editorial em 2019, a obra Formação da Coleção Latino-Americana do MoMA: Arte, cultura e política (1931-1943), propõe historicizar os primeiros anos de funcionamento do Museu de Arte Moderna de Nova York, refletindo sobre a criação e trajetória do acervo de obras latino-americanas da instituição. O livro em questão é uma versão revisada da dissertação de Eustáquio Ornelas Cota Jr., defendida no Programa de Pós-graduação em História da Universidade de São Paulo em 2016. Mobilizando um grande levantamento de documentos institucionais do MoMA, o historiador problematiza a constituição da coleção latino-americana do museu, entrecruzando esse processo às dimensões culturais e políticas das relações entre Estados Unidos e América Latina.

Eustáquio Ornelas Cota Jr. defende a articulação da instituição com a política da Boa Vizinhança, especialmente pela atuação da família Rockfeller, tendo Nelson Rockfeller sido presidente do MoMA. Além da relação política e consonância com um projeto de imperialismo estadunidense instaurado na gestão de Franklin D. Roosevelt, o historiador também aborda a problemática das identidades latino-americanas ao considerar que a formação dessa coleção de arte foi fundamental para a construção de discursos e representações sobre as culturas latinas sob a perspectiva dos Estados Unidos. Como tese central, a obra defende "a confluência entre as diretrizes da chamada política da Boa Vizinhança vigente nos Estados Unidos desde 1933 e a decisão de ampliar a inicial coleção de arte moderna mexicana, transformando-a em latino-americana". (p. 215).

Estruturada em três capítulos, para além de introdução e conclusão, a obra se insere no campo da História da Arte nas Américas, em interface com a História Cultural e a nova História Política. A partir dos estudos de Peter Burke, Eustáquio Ornelas Cota Jr. considera que a arte não pode ser "desconectada do contexto e dos conflitos culturais do momento histórico, nem tampouco ela se configure apenas como um mero reflexo do contexto social. A arte atua para a construção de sentidos e se torna um importante testemunho do processo histórico" (p. 19). Neste sentido, sua abordagem parte de um estudo ampliado da arte, considerando-a como uma produção humana e um produto de seu tempo, mas que é constantemente ressignificada sob o olhar e a ação do "presente" dos sujeitos que a mobilizam. Essa perspectiva, parte de leituras contemporâneas do historiador da arte Georges Didi-Huberman, influenciada pelas teorias da montagem de Aby Warburg, compreendendo a existência de múltiplas relações entre imagem e tempo. ${ }^{1}$ Como destaca Maria Bernardete Ramos Flores, essa abordagem considera que "as imagens têm uma história, mas o que elas são, seu movimento próprio, seu poder específico, só aparecem na história como 'sintoma' de durações heterogêneas: a

${ }^{1}$ Cf.: DIDI-HUBERMAN, Georges. Ante el tiempo: historia del arte y anacronismo de las imágenes. Buenos Aires: Adriana Hidalgo, 2015. 
abertura repentina para um tempo pretérito e a aparição de uma latência ou de uma sobrevivência; da estranha conjugação entre diferença e repetição". ${ }^{2}$

O primeiro capítulo da obra, "O MoMA e a formação de sua coleção latino-americana", aborda a criação do projeto do Museu de Arte Moderna de Nova York a partir de documentos institucionais disponíveis no próprio acervo da instituição, como press releases e publicações oficiais. Ao analisar o início do projeto do museu, Cota Jr. defende o protagonismo feminino na fundação, com destaque para três mulheres da elite estadunidense: Lillie P. Bliss, Mary Quinn Sullivan, Abby Aldrich Rockefeller. O MoMA, que abriu as portas oficialmente em 07 de novembro de 1929, tinha como pretensão ser uma das instituições de referência mundiais sobre arte moderna, projeto que foi capitaneado pelo historiador da arte Alfred Barr Jr., convidado a ser o primeiro diretor do museu. Segundo o autor, Alfred Barr Jr. possuía uma visão bastante ampla sobre o que seria a arte moderna, defendendo que as características desta classificação só poderiam ser percebidas pelas próprias obras.

Alfred Barr foi central para o estabelecimento do projeto do MoMA como um espaço aberto a experimentações artísticas, o que afastou o museu de outras instituições já consolidadas na mesma cidade como o Metropolitan Museum of Art. Apesar desse perfil, isso não significou que o MoMA estivesse fora de seu contexto social e político. Mesmo com o financiamento de elites locais e o apoio da família Rockfeller, o museu foi criado em um período de recessão econômica e da crise de 1929, o que contribuiu para que se criassem projetos de exposições temporárias e circulares em diferentes regiões do país e do continente americano. A ideia das exposições de circulação foi fundamental, segundo o historiador, não apenas para a manutenção financeira da instituição, mas também para a divulgação do MoMA e, principalmente, para constituição de seu acervo criado a partir de dois perfis de aquisição de obras: doações e compras.

Neste primeiro capítulo, Eustáquio Ornelas aborda os primeiros passos da constituição da coleção latino-americana do MoMA, iniciada em 1935 com a doação da obra Subway de Orozco pela Sra. John D. Rockefeller. Destacando a aquisição de obras de países como México e Brasil, o historiador aponta para o alinhamento da formação da coleção com as diretrizes da política externa estadunidense para o continente latino-americano. Uma das contribuições principais do autor neste capítulo é a observação da tentativa de construção de representações sobre a América Latina visando a trabalhar um imaginário sobre as culturas latino-americanas pela população (em especial a elite) estadunidense. Além disso, o acervo do museu (que continha também obras de artistas estadunidenses) foi utilizado na criação de exposições itinerantes específicas para a América Latina, integrando os projetos do Office of the Coordinator of Inter-American Affairs.

O segundo capítulo da obra, intitulado "O catálogo da coleção e a história da arte latinoamericana contada por Lincoln Kirstein" analisa a principal fonte na qual se baseia o estudo: o

\footnotetext{
${ }^{2}$ FLORES, Maria Bernardete Ramos. Olhar para as imagens como arquivos de histórias. Territórios e Fronteiras (Online), v. 8, p. 239-255, 2015, p. 250.
} 
catálogo da exposição "The Latin-American Collection of the Museum of Modern Art" (1943). A partir da publicação, o historiador problematiza a narrativa e o projeto cultural de criação da coleção latino-americana no MoMA, com destaque para o ensaio sobre a história da arte latina publicado por Lincoln Kirstein, consultor de arte latino-americana, no catálogo. Reflete-se sobre a construção do próprio acervo, e da equipe que dirigia o museu em 1943, defendendo que tal formação não pode ser vista como um empreendimento individual ou excluído de seu contexto, para em seguida se pensar quais eram os principais países representados no MoMA.

Países como México e Brasil seguiram ocupando as primeiras posições na nacionalidade das obras presentes na coleção, mas foi registrado um crescimento no número de obras argentinas e cubanas. Ao analisar os países de origem das obras, Cota Jr. considera que a coleção em 1943 estava "longe de ser um conjunto amplamente representativo no que se refere à arte produzida nos países da América Latina" (p. 104). Esse aspecto problemático é um dos pontos de tensão entre o acervo existente e o discurso que o próprio museu procurava elaborar, no qual se defendia um "empreendimento pioneiro" da instituição e do qual a instituição seria referência global.

Com relação à análise do texto de Lincoln Kirstein, intitulado "Latin-American Art", o historiador afirma que sua publicação no catálogo "possui grande importância para os nossos estudos, pois as ideias nele contidas colaboraram substancialmente para embasar as visões da instituição sobre o tema, afinal, o editor era o consultor de arte latino-americana do MoMA na época". (p. 106). Dividido em nove partes e em dois recortes temporais (antes e após as independências latino-americanas), o texto de Kirstein abordaria as produções de artistas latino-americanos, juntamente aos norte-americanos e europeus. Essa aproximação com artistas estadunidenses e europeus ocorria, principalmente, como forma de comparação e relação visando a explicar a arte latino-americana, produzindo uma representação sobre as identidades culturais e artísticas do continente. Um dos principais aspectos a esse respeito é a construção de uma visão dicotômica, apesar de por vezes aproximadas, entre latinos e estadunidenses, referenciados muitas vezes como "nós" e "eles" ou "os daqui" e "os de lá".

Em "A arte moderna na América Latina", terceiro e último capítulo, o autor prossegue com a análise do catálogo The Latin American Collection of The Museum of Modern Art, com foco nas análises de Lincoln Kerstein sobre a arte moderna na América Latina. O texto de Kerstein, que parte das próprias obras do acervo, é analisado por Cota Jr. juntamente as imagens presentes no catálogo, em articulação com outras fontes institucionais como relatórios e comunicados. Como questão central, o autor problematiza as "escolhas realizadas para compor a coleção, preferencialmente as indicações de artistas e obras ressaltadas nos textos e imagens no documento e que justificaram artisticamente o empreendimento do MoMA". (p. 159). O historiador observa também a construção de textos específicos para definir a arte moderna em cada país da América Latina, que foram construídos a partir de biografias, comparações e relações de influência entre a arte latino-americana e o que seria definido como 
uma arte "mundial", visando a orientar o leitor do catálogo e o visitante das exposições que usaram dessa coleção nos debates.

Segundo Cota Jr., os escritos de Lincoln Kerstein sobre a arte moderna na América Latina procuraram pontuar aspectos gerais e datas marcantes dos movimentos em cada país, como no caso do muralismo mexicano. Sobre as obras de artistas como Diego Rivera, José Clemente Orozco e David Alfaro Siqueiros, o responsável pelo departamento de arte latinoamericana do MoMA construiu uma narrativa que "demonstra a preocupação do autor em indicar a relação entre a produção artística mexicana e o processo histórico ocorrido a partir de 1910". (p. 166). Ainda sobre o México, o autor destaca que, na perspectiva do catálogo produzido pelo MoMA, os Estados Unidos seriam os principais colecionadores e consumidores de arte mexicana, conferindo ao país um lugar de patrono e principal divulgador desse gênero.

Tais aspectos, problemáticas e contradições sobre a representação da arte latinoamericana são observados também nas análises sobre outros países como Brasil, Argentina e Cuba. Neste sentido, Cota Jr. percebe a dimensão não apenas discursiva presente na constituição da coleção, mas também a centralidade da curadoria no processo de seleção e aquisição de obras que foram "guiadas pela avaliação do MoMA sobre a relação entre os países e seus respectivos estágios de desenvolvimento e produção da arte moderna local, considerando as opiniões dos principais especialistas representantes do museu, que definiam o que deveria ou não ser valorizado na arte moderna de cada país". (p. 178). A respeito dos processos de curadoria e da própria coleção, o autor encerra o capítulo analisando três conjuntos do acervo: o muralismo mexicano, as obras de Candido Portinari e as "novas" perspectivas para a arte moderna.

O livro de Eustáquio Ornelas Cota Jr. contribuiu diretamente para os estudos sobre a História das Américas e da Arte Latino-americana. Ao tematizar a formação de uma coleção do MoMA a obra possibilita perceber as relações entre arte, política e construção das representações de identidades latino-americanas nos Estados Unidos como forma de problematizar as relações entre o país e o restante do continente. Destaca-se, em especial, o esforço do autor em demonstrar que, como um projeto das elites que integrou as políticas da Boa Vizinhança e do imperialismo estadunidense, o MoMA contribuiu diretamente para formação de imaginários sobre as Américas a partir da arte, sendo a função da curadoria e a reflexão sobre a arte moderna elementos centrais de reflexão. 